\title{
MAHABAT KHAN MOSQUE - AN ISLAMIC SYMBOL OF PEACE
}

\author{
Shabbirullah Qureshi* \\ Dr. Mohammad Ashraf Khan**
}

\begin{abstract}
It is ironical that the Mughals are remembered as warriors yet their breathtaking architecture offers an inspiration for regional peace. Separatist narratives may attempt to emphasise the ideological differences in the Indian subcontinent, but the centuries-old resonance of architectural magnificence of the Taj Mahal in India and the Shalimar Gardens in Pakistan simply mocks any divisions. It is within this perspective that the preservation and restoration of the Mahabat Khan Mosque in Peshawar deserves more attention than it has been accorded. Papers published so far have served well by detailing its history and features, but its significance as the western-most unifier for the sub-continent has been left unexplored. This article aims to highlight the link that its architectural features create with the Mughal buildings of the whole subcontinent. Photographs from unique angles are shared to highlight this commonality and thus serve as a counter narrative of regional unity based on a common Islamic architectural heritage. Also included is a fresh inventory of its state of disrepair, based on a survey conducted by students of City University in 2019, to revoke attention towards its restoration. Finally, recommendations are offered to address the delay in relocation of surrounding shops that is currently hindering its repair.
\end{abstract}

Keywords: Mahabat Khan Mosque, Peshawar, Conservation, Mughal Architecture.

\section{INTRODUCTION}

Whereas ideological extremist narratives may be against peace between Pakistan and India, these two rivalling countries actually happen to share a common Islamic architectural heritage. These countries form a major portion of the region that functioned as a single subcontinent since the Mughal period of the earlier to mid part of the second millennium, and continued during the British Raj of the later part of the millennium. Hence, there are many shared commonalities in the two societies before they became two separate countries, such as similarities in currencies, administrative infrastructure, railway networks, irrigation canal systems, and many others. None of these are perhaps so viscerally powerful though as the Mughal architectural legacy that has survived over time and adorns both cultures till today. Just as the Taj Mahal sways hearts of visitors in India, so does Shalimar Gardens leaves viewers with a deep sense of awe in Pakistan. There are many such masterpieces in both countries that are undeniably linked together in terms of a distinct architectural style and resulting intensity of aesthetic splendour. This article attempts to advance the documentation of one of these grand buildings, namely the Mahabat Khan Mosque in Peshawar, as the western most marker of the tradition.

A number of documentation works on the Mahabat Khan Mosque have already recorded its history in detail, including drawing comparisons with other examples of Mughal Architecture, but its significance as a symbol of peace has as yet remained unexplored. This paper aims to highlight the architectural features that link it with the heritage buildings of that period in the whole subcontinent. These features are discussed after a brief review of relevant literature, accompanied by photographs that focus on their visceral quality in particular. It is in this backdrop of its significance that the importance of its current state of disrepair can be comprehended. Recently students of the Architecture Department of City University, Peshawar compiled a cursory inventory of the types, locations and extent of repair required

* Shabbirullah Qureshi, University of Engineering and Technology, Peshawar, Pakistan. Email Correspondence: shabir_q65@yahoo.com

** Dr. Mohammad Ashraf Khan, City University, Peshawar, Pakistan. Email correspondence: mak.weplan@gmail.com 
urgently. Results are presented in a tabulated form, followed by a set of recommendations for addressing the present hindrance in execution of repairs due to delay in relocation of shops surrounding the building. It is imperative to adopt a participatory approach for arriving at a consensus of all stakeholders, in order to restore this significant building.

\section{LITERATURE REVIEW}

Mughal Architecture, its history and significance is already the subject of numerous books (Alfieri and Borromeo, 2000; Ardalan and Bakhtiar, 1999; Brown, 2013; Dani, 1995; Foster, 2004; Frishman, Khan, and Al-Asad, 2002; Hussain, 1998), therefore it is sufficient to focus on those works that are relevant specifically to the Mahabat Khan Mosque. Foremost among these are the series of papers by Shah (1996, 1997, 1999), while earlier works on this topic include a mid-twentieth century documentation by Jaffar (1940). These papers have documented the history of this building, include a comparison study, and details of its calligraphic ornamentation (Jaffar, 1940; Shah, 1996, 1997, 1999). In the present paper the aim is to add to the subject by highlighting the aesthetic quality links between the Mahabat Khan Mosque and the whole oeuvre of Mughal masterpieces spread across both Pakistan as well as India. To this end it can be useful to begin with a brief recollection of specifically the roots of aesthetic decisions embedded in Mughal era buildings, in order to set the context for the discussion.

A number of authors' accounts suggest that Mughal Architecture is marked by Babur's conquest of Delhi in 1526, and especially his son Humayun's decision to bring craftsmen from Persia to instigate a fusion of Persian and Indian architecture styles, as best illustrated in the Emperor's tomb that was built after his death in 1556 (Alfieri and Borromeo, 2000; Ardalan and Bakhtiar, 1999; Brown, 2013). This fusion matured during the syncretism-oriented rule of their descendent Akbar, whose period of rule extended till the beginning of the 17th century, as embodied in the palaces and related buildings of the new capital he built at Fatehpur Sikri (Alfieri and Borromeo, 2000; Ardalan and Bakhtiar, 1999; Brown, 2013). Buildings of this era were mostly constructed with red stone using trabeated techniques, often including marble inlays, heavy domes and multifaceted columns with bracings(Alfieri and Borromeo, 2000; Ardalan and Bakhtiar, 1999; Brown, 2013). Chhatris (kiosks) were also common and the interior walls and ceilings were at times painted with coloured patterns (e.g. Alfieri and Borromeo, 2000; Ardalan and Bakhtiar, 1999; Brown, 2013). It should be noted that Fatehpur Sikri's Friday Mosque (1568-78) is considered by scholars as the first of the great courtyard mosques of Mughal cities (Frishman Khan, and Al-Asad, 2002; Lewcock, 1995).

Shah Jahan's reign (1628-58), marks the classic period within Mughal Architecture, due to its immaculate use of symmetry and uniformity of shapes (Frishman, Khan and Al-Asad, 2002; Lewcock, 1995). White marble and highly polished white stucco from Gujarat replaced red sandstone, and the architectural vocabulary was streamlined to a set number of elements (Frishman Khan, and Al-Asad, 2002). 'Shahjahani' columns were multifaceted and tapering, with cusped arches, foliated bases, and muqarnas or vegetal capitals (Frishman Khan, and Al-Asad, 2002; Lewcock, 1995). Arches were multi-cusped, and a full bulbous form was used for domes, with constricted necks (Frishman Khan, and Al-Asad, 2002; Lewcock, 1995). Decorative motifs consisted of naturalistic flowering plants, and pietra-dura inlays replaced the earlier stone intarsia patterns (Frishman, Khan and Al-Asad, 2002; Lewcock, 1995). Mosques would have multiple minarets, of cylindrical or octagonal plan, with one or more balconies and topped by chhatris (Frishman Khan, and Al-Asad, 2002; Lewcock, 1995).

While general characteristics of the mosques of this period have already been described in detail in published literature (Alfieri and Borromeo, 2000; Ardalan and Bakhtiar, 1999; Brown, 2013; Frishman, Khan and Al-Asad, 2002; Lewcock, 1995), the aim here is to recall the key aesthetic characteristics relevant to the Mahabat Khan Mosque. Overall the mosques would comprise a rectangular courtyard or sahn, enclosed on the four sides by pillared cloisters or iwans, with a fountain or tank in the centre for ablution. There would be a rectangular hall on the qibla or Mecca-facing side, with the front wall containing a recess or alcove called a mihrab, where the prayer would be lead from. On the right side of the mihrab would be the pulpit or mimber, and there would be high towers or minarets on the sides and at times at all four corners of the mosque. Due to the prohibition of faces of living beings in Islam, decorative lettering and geometric patterns became increasingly sophisticated, using different coloured marble, painted plaster, fresco and glazed tiles (Foster, 2004).

In terms of structural advancements, arches and domes gradually replaced the post and beam systems (Alfieri and Borromeo, 2000; Ardalan and Bakhtiar, 1999; Brown, 2013; Frishman, Khan and Al-Asad, 2002; Lewcock, 1995). Techniques were used to counter the effect of oblique or lateral thrust and to resist the forces of stress and strain, by means of which greater strength and stability was achieved. Eventually there was an effect on the skyline, flat or low- 
pitched roofs were replaced by domed roofs, creating a shift from pyramidal to ovoid forms (Shah, 1999).

Along with the significance of Mughal Architecture it is also important to understand the strategic position of Peshawar in the region (Hussain, 1998). This is the city where Alexander's army passed through in 327 B.C. In the past, it has been mentioned by different names, until the Mughal Emperor Akbar gave it the present name (Hussain, 1998; Shah, 1999). Many scholars, traders, merchants, historians and conquerors have passed through it while navigating the nearby Khyber Pass to cross the Karakoram Mountains to and from neighbouring Afghanistan. Hospitality is a conspicuous attribute of this region's culture (Hussain, 1998). Peshawar is among the few ancient cities in the sub-continent that have retained their character. Mughal Emperors' heritage has survived in the form of buildings such as Mahabat Khan Mosque, Tomb of Nawab Saeed Khan, Gor-Khatri, Bala Hisar Fort, Tomb of Qutb-ud-Din and Tomb of Shaikh Imamad-Din. Materials used in these buildings include burnt brick, lime mortar and plaster as the main materials, while the architectural features include different type of arches (pointed arch, multi-foil arch, cusped arch and shoulder arch) and domes (Hussain, 1998). Among the decorative motifs the most important techniques are tempra and fresco painting, stucco tracery, stalactite, arabesque, mosaic, relief work and calligraphy (Dani, 1995; Foster, 2004; Hussain, 1998; TCKP, 2018).

Mahabat Khan Mosque is thus significant as a point of convergence between the Mughal heritage on one hand and the strategic location of Peshawar as the western-most demarcation of the region. Unfortunately, there is no architectural record of the Mosque. Documentation of the early British occupation of Peshawar mentions only the desecration of the mosque in 1834 under the Sikh rule (Shah, 1996, 1997, 1999). No record of repairs or additions was kept by its mutawwalis, or caretakers, while numerous renovations and improvements were undertaken after the 1947 independence of Pakistan (Shah, 1996, 1997, 1999). Therefore, the description that follows is an observational discussion of its features that connect it with Mughal Architecture as a whole.

As mentioned at the outset the contribution of this paper is to propose an additional context for placing the documentation works already completed on the Mahabat Khan Mosque, namely as a harbinger of a narrative of commonality and peace between India and Pakistan, on the basis of a celebration of the awe-inspiring features of the building. This approach of highlighting the role of architecture as a conscious means for peace-building and socio-cultural harmony within situations of diversity and conflict is a relatively fresh topic. However, a number of authors' works having already established it as a distinct subject of published discourse, including foremost, the specific reference to peace as a purpose of architecture by Gray and Hancock (2007). These authors have also used photographs to convey the experiential aspect, as is the case in the present article as well (Gray and Hancock, 2007). Whereas such works have focused on the effects of architecture on creating a feeling of peace, the present article reaches beyond to suggest commonalities of similar experiences as a means for bonding and resolving conflict (Day, 2007; Sternberg, 2009).

\section{ARCHITECTURAL FEATURES - EXPERIENTIAL QUALITY OF THE MAHABAT KHAN MOSQUE}

In the architectural design analysis that follows the focus is on the experiential value that makes Mahabat Khan Mosque belong to the shared Mughal architectural heritage of the whole region, occupied by Pakistan and India together. As such this endeavour functions as a reinterpretation of previous documentations for the specific purpose of highlighting the feelings of awe that the visitors experience to date (Buttimer and Seamon, 2015). These feelings are a common trait across all monuments of Mughal Architecture found in India as well as Pakistan, and hence are a potential source for creating a connection across these two otherwise politically divided nations (Brown, 2013; Frishman, Khan and Al-Asad, 2002). This connection has the potential to serve as a counternarrative of unity and peace, in the face of prevailing separatist narratives of difference and violence. To fulfil this objective major design decisions have been discussed, beginning first with the selection of the Mosque's site, followed by descriptions of other key elements. Care has been taken to include images that present views and angles of vision befitting an architectural gaze, and are radically different from the multitude of tourism-oriented images already available for public viewing on the world wide web.

\section{Spectacular Selection of Site}

Proximity to the ancient site of Gor Khatri (Shah, 2016), suggests that the Mosque was planned to function as an unequivocal landmark, not just as a statement of power but also as a cultural symbol of exemplary hospitality for travellers. It is situated on the boundary of the centuriesold walled city, possibly to serve caravans passing through the Grand Trunk Road and nearby traveller accommodations, or caravan serais. Towering minarets must have indeed made it visible from far distances, imaginably providing a 
sight of relief and expectations of a tranquil place to take rest for traders from Central Asia on one side and India on the other, travelling long distances on animal-drawn modes of transport of that time, as evident even to this day (Figure1).

It was conveniently near the old Qissa Khawani bazaar (literal meaning: story-telling market). There was the Mahabat Khan serai just beside, on the eastern side of the Mosque right next to the Qissa Khawani bazaar. Indeed the careful selection of sites with the architectural consideration of providing an iconic approach to strategic buildings is a common characteristic found in almost all monuments of the Mughal era, including those present in present day India, namely among many examples, the Grand Mosques at Fatehpur Skri and at Delhi (Alfieri and Borromeo, 2000; Brown, 2013; Shah, 1999).

\section{Composition of Strength and Stability - Pervading Feeling of Amity}

Along with the use of classic symmetry, the overall aesthetic character of the building is of massiveness and stability. Its towers are slightly tapered towards the top, while the width to height ratios of the arches and domes all portray a feeling of horizontality, as illustrated in the views generated at various points in the courtyard and interior hall of the building (Figures 2-5). Also, the size of the courtyard and the overall size versus height ratio of the building as a whole returns back a sense of a large vastness to the beholder, again a well-known feature of all mosques built in the Mughal period (Brown, 2013; Jaffar, 1940; Lewcock, 1995).

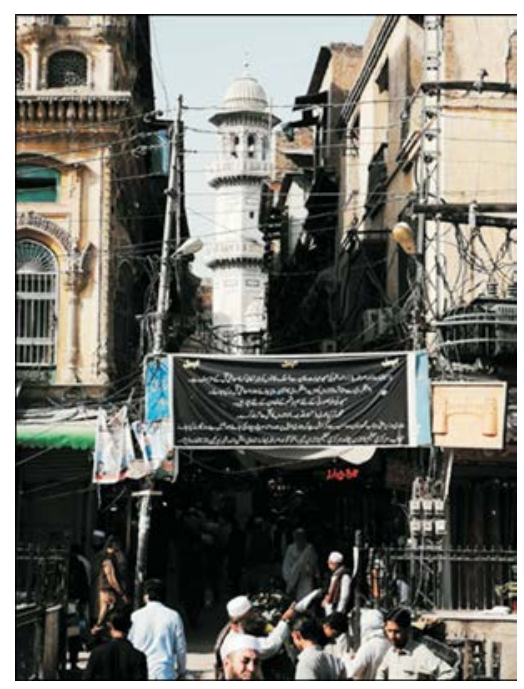

Figure-1: Strategic location of the mosque allows it to be visible from far distance.

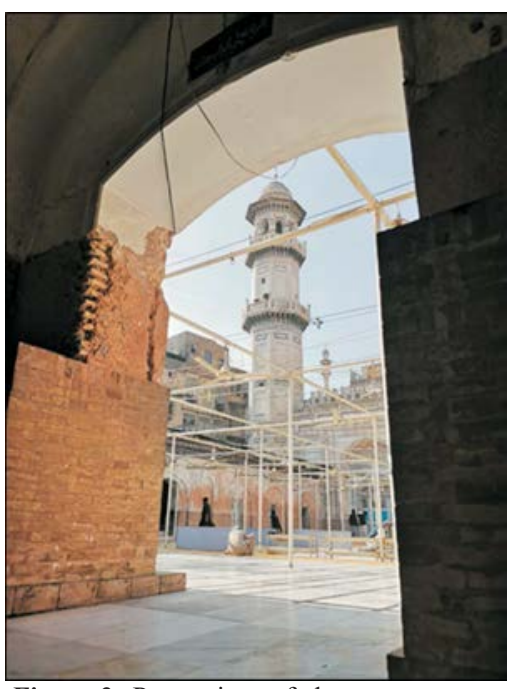

Figure-2: Proportions of elements portray a feeling of stability and amity- broad and massive looking towers.

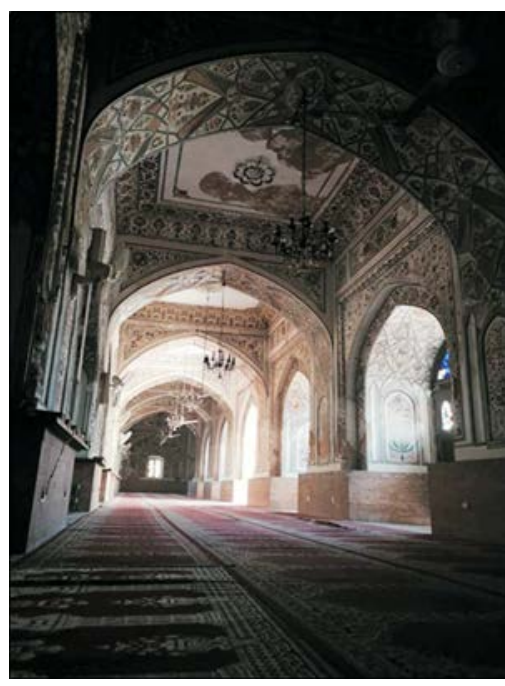

Figure-3: Proportions of elements portray a feeling of stability and amity - tick walls and broad arches.

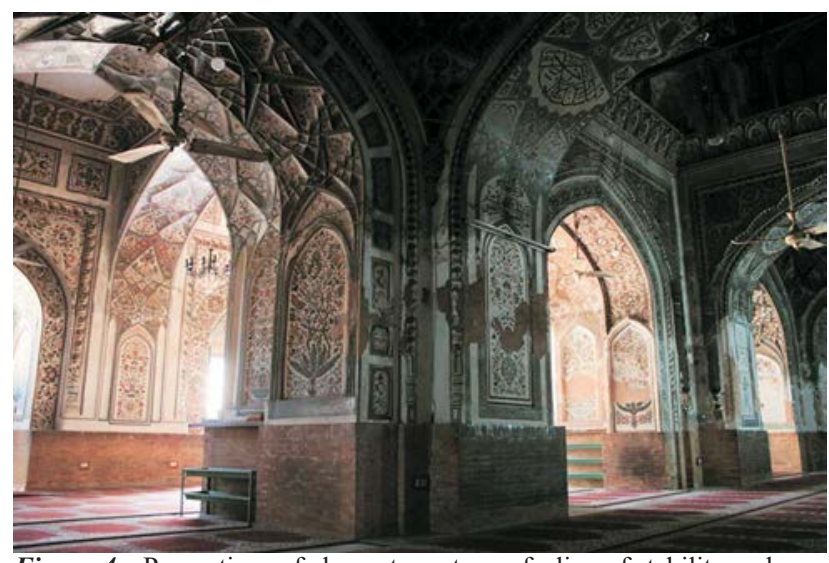

Figure-4: Proportions of elements portray a feeling of stability and amity - massive central columns.

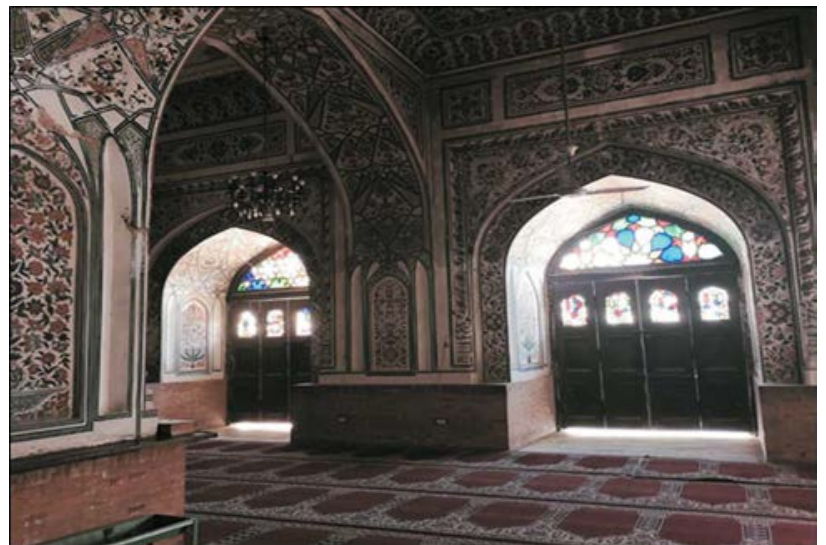

Figure-5: Proportions of elements portray a feeling of stability and amity - deeply recessed openings. 


\section{Exquisite Relief Work}

Columns and arches have been presented throughout the building as an exquisite composition of relief gradations (Figure 6). Every edge and plane surface has been treated to create a pervading effect that traverses the whole building, in the exterior as well as the interior (Figures 7-10). Depths and widths of each level in the vertical gradations have been carefully chosen to deliver a sense of aesthetic ambience par excellence (Jaffar, 1940; Shah, 1999). It is reminiscent of the similar effect that can be experienced at the Grand Mosques found in India at Fatehpur Sikri and Delhi, as well as the Taj Mahal complex in Agra (Ardalan and Bakhtiar, 1999; Brown, 2013).

\section{Ornamented Towers and Fluted Domes - Delicate Mass}

Almost all of the monumental mosques of the Mughal period have domed roofs (Ardalan and Bakhtiar, 1999; Brown, 2013). However, fluted or ribbed domes are not so common, and therefore the Mahabat Khan Mosque's closest similarity is with the ribbed dome roof of the Grand Mosque of Delhi, India (Shah, 1999). Although the flutes of the domes of the Mahabat Khan Mosque were added in the British colonial period, it can be assumed that this addition was inspired by the original design, considering the scale and expanse of the restorative work undertaken at that time (Shah, 1999). As such it suggests an unmistakable heritage connection with the grooved dome of the Grand Mosque of Delhi

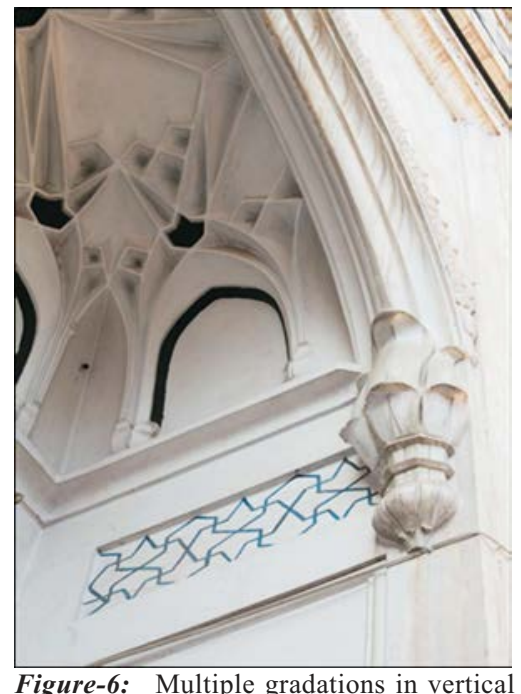

relief work creates a feeling of $\mathrm{rich}$ yet sublime embellishment.

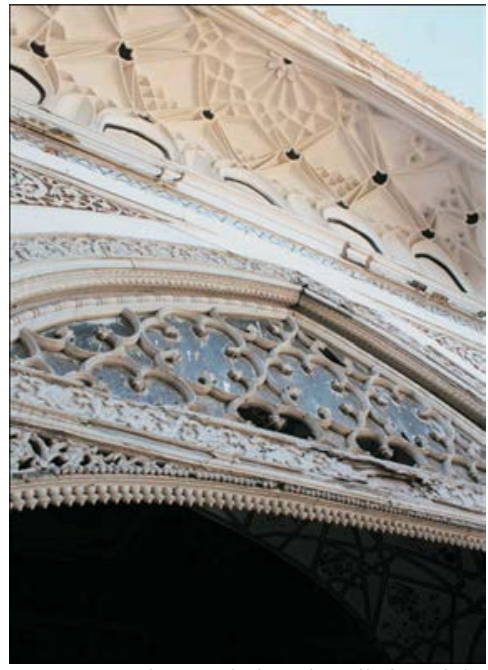

Figure-7: Fine gradations in relief work in arched openings combined with geometric designs create a feeling of rich yet sublime embellishment.

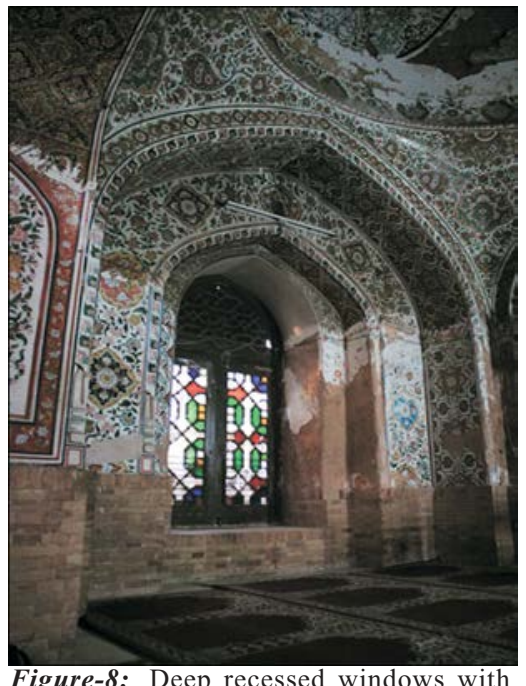

Figure-8: Deep recessed windows with multiple arches within arches.

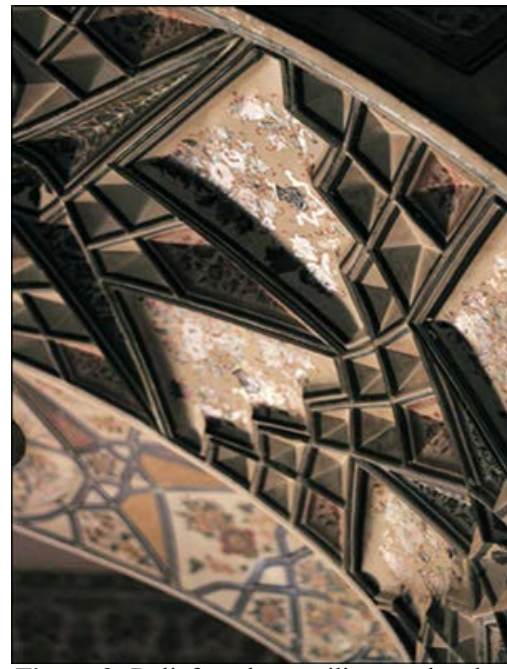

Figure-9: Relief work on ceilings and arches in the interior of the mosque,

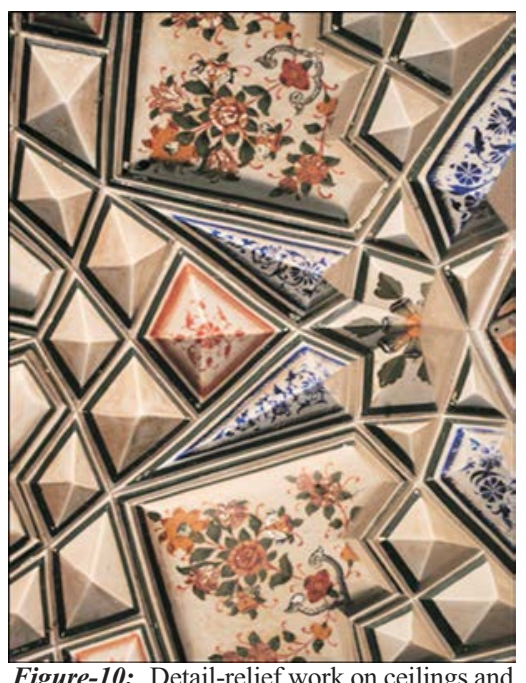

Figure-10: Detail-relief work on ceilings and arches in the interior of the mosque. 
(Alfieri and Borromeo, 2000; Ardalan and Bakhtiar, 1999; Frishman, Khan and Al-Asad, 2002). A point of interest here is that the Persian style of that time had plane domes, therefore it is probable that the idea of fluting was inspired by the tradition prevalent for this type of dome construction in Central Asia (Foster, 2004; Jaffar, 1940; Shah, 1997, 1999). Similarly, the detailed decoration work on the towers portrays a feeling of delicate mass (Figures 11-12).

\section{Climatic Ambience}

All Mughal buildings bear witness to a strong tradition of climate control understandings and their implementation. Use of brick in the Mahabat Khan Mosque, combined with thick walls, generous openings for ventilation, light niches at the sides of domes, and a central courtyard with a water body, are all environmentally responsive features found in all Mughal buildings (Jaffar, 1940; Lewcock, 1995; Shah, 1997). Similar decisions are visible in the Grand mosques

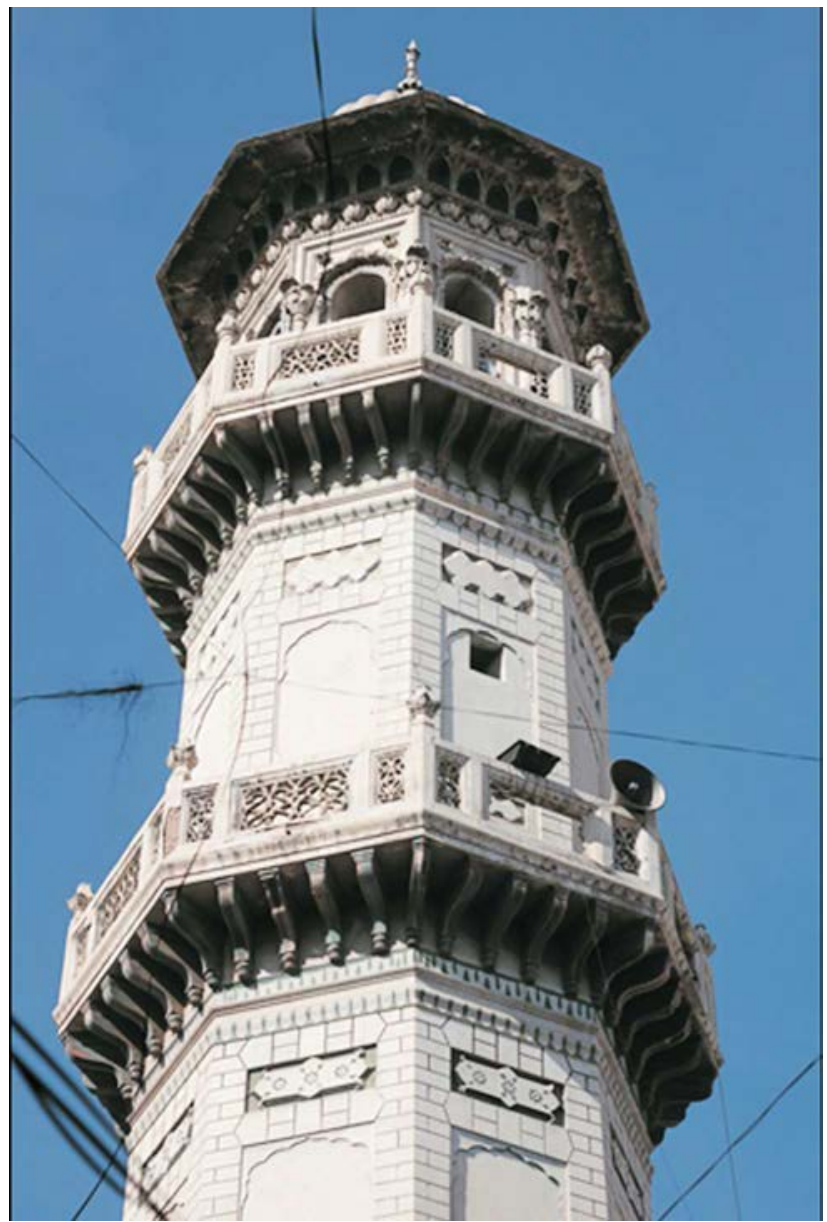

Figure-11: Intricate decorative work on huge towers portrays a feeling of delicate mass. at Delhi, Fatehpur Sikri as well as Agra (Brown, 2013). Photographs show the small niches given at the base of the domes to allow natural sunlight to illuminate the west side walls of the Mosque (Figures 13-14).

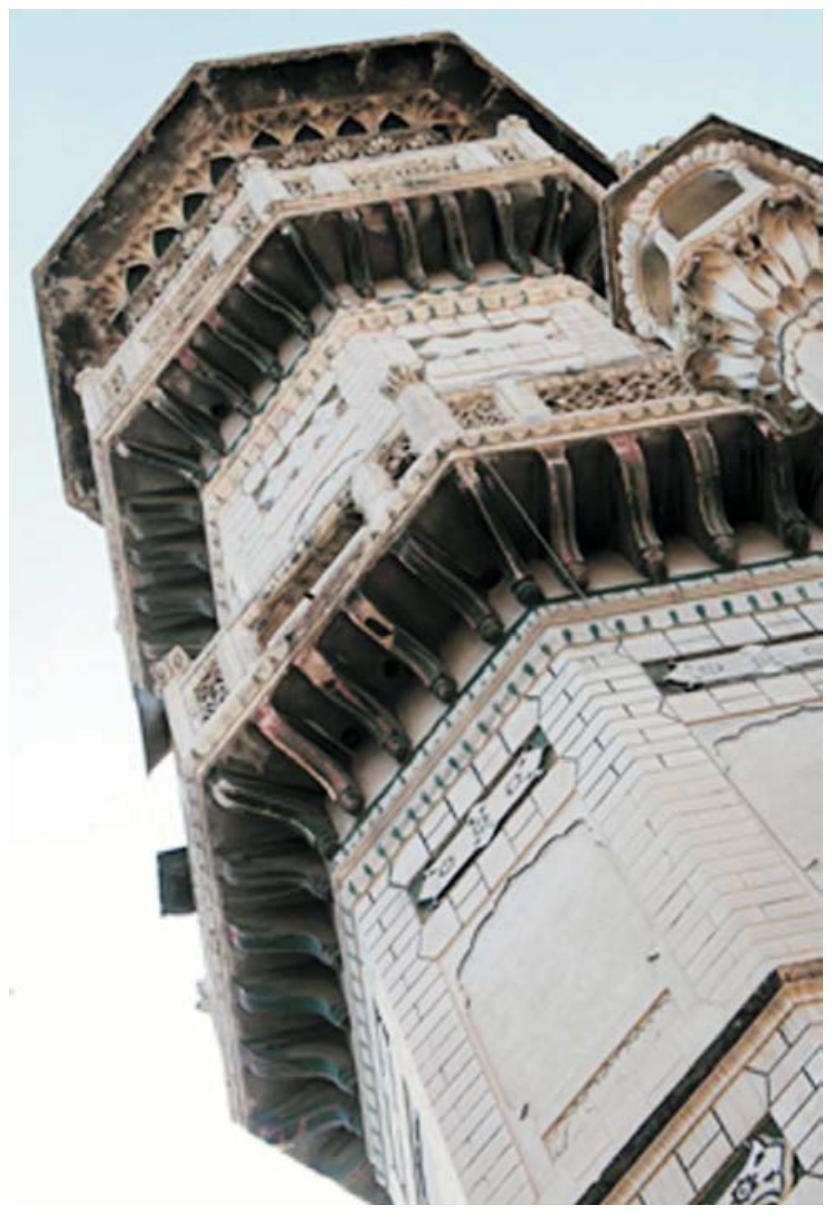

Figure-12: Close-up view-intricate decorative work on huge towers portrays a feeling of delicate mass.

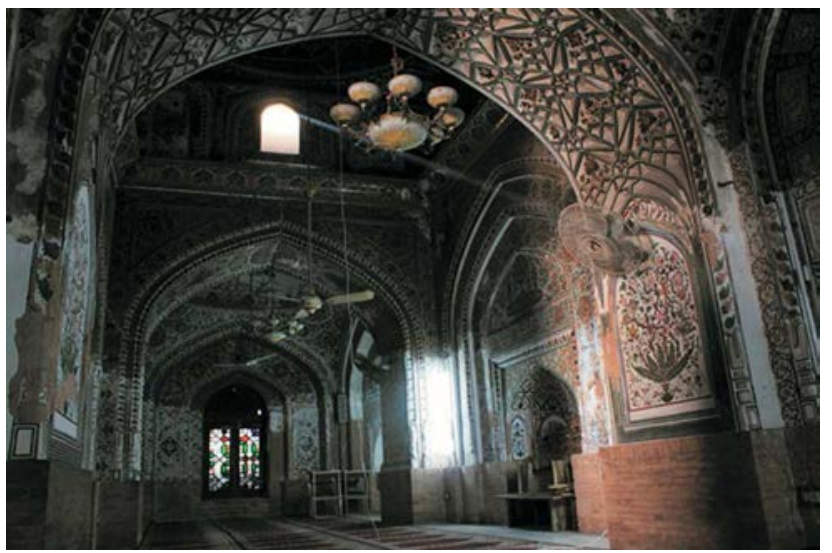

Figure-13: Small niches given at the base of the domes to allow natural sunlight to illuminate the west side walls of the mosque. 


\section{Sophisticated Interior Theme - Balance of Colours and Motifs}

Mughal Architecture has a distinct quality of interior treatments all over the subcontinent (Lewcock, 1995; Shah, 1996). This is observable in the use of colours and carefully designed motifs of the Mahabat Khan Mosque (Shah, 1996). These decorations are closely similar in aesthetic sophistication to those found in buildings in India, and in turn with the splendour of Persian architecture that is the inspiration of the Mughal craftsmen (Ardalan and Bakhtiar, 1999; Brown, 2013). For example, the finely proportioned fenestrations in the Agra Mosque and the Delhi Mosque create a transcendent aesthetic feeling of balance and vivid yet ambient use of complimentary colours (Brown, 2013; Foster, 2004; Frishman, Khan and Al-Asad, 2002). This same feeling is observed in the Mahabat Khan Mosque, as visible in the photographs taken in an attempt to capture the experience (Figures 15-18). Figure-15 is a panoramic view of the interior, showing the overall tone of the scheme, while the rest of the views portray the translation of the quality into each detail of each and every part of the interior.

\section{Restoration and Preservation}

Above discussion demonstrates the significance of this building on one hand, while the pictures also reveal its current state of disrepair and disintegration. A brief listing of previous works undertaken for its restoration and preservation is shared to highlight the urgency of a fresh investment. Since a number of publications by other authors have already discussed these works in detail it is sufficient to only recall the key aspects here.

Original documentation of the Mosque is absent in historical records, and only a few sources provide clues about its origins and repair works (Shah, 1999). In one of the sources

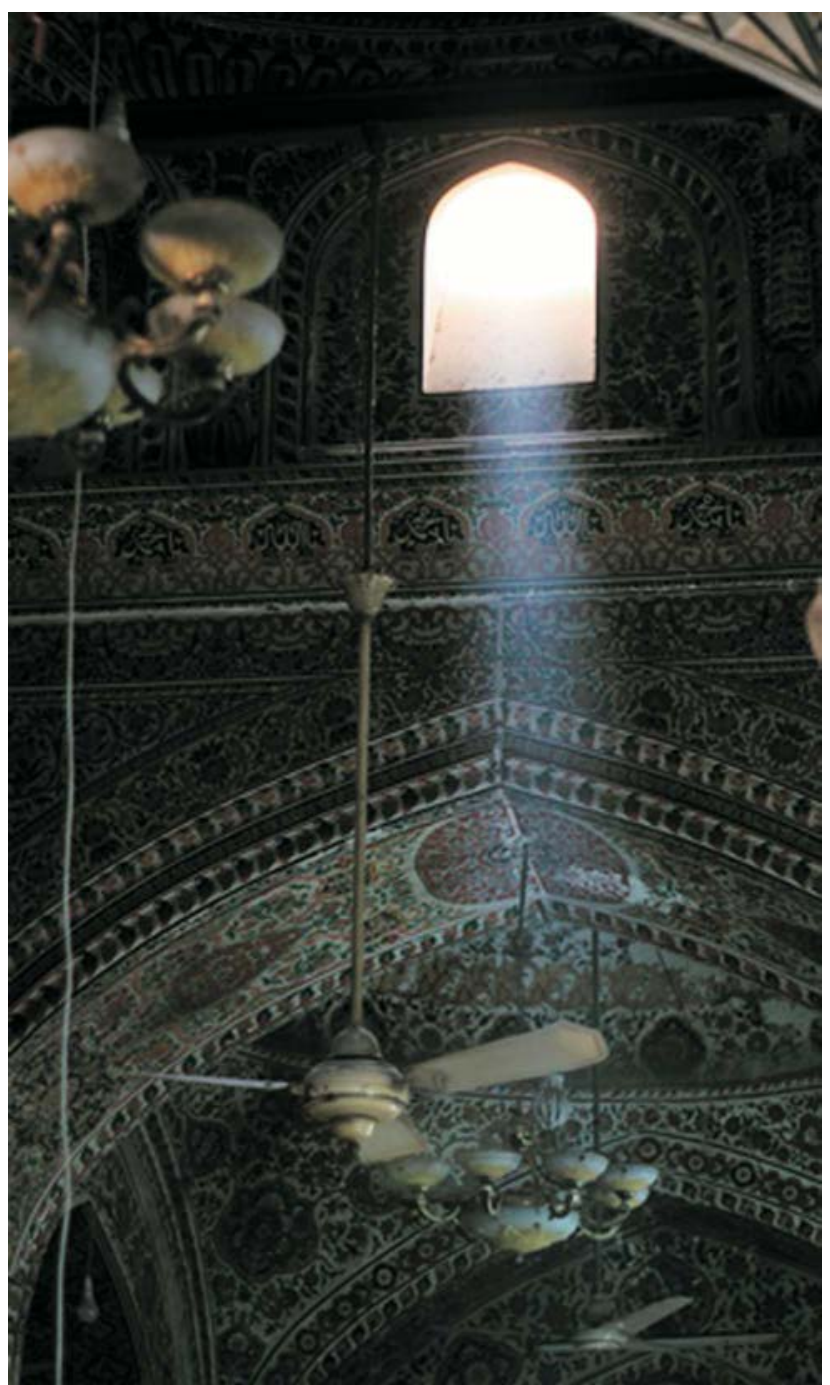

Figure-14: Detail-small niches given at the base of the domes to allow natural sunlight to illuminate the west side walls of the mosque.

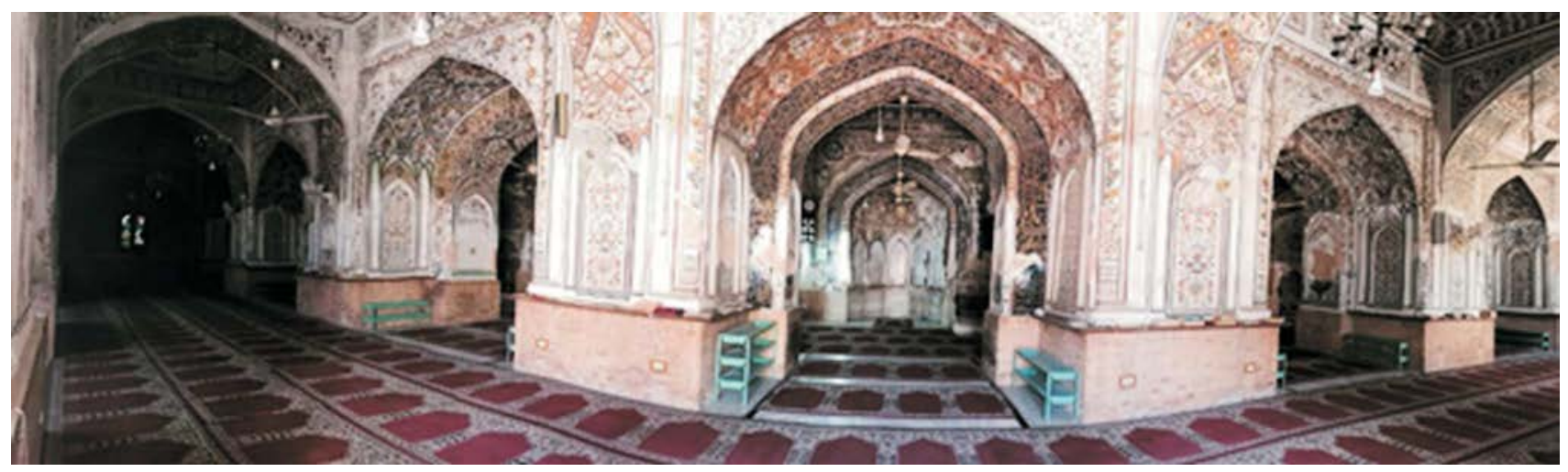

Figure-15: Panoramic view of the interior, showing the overall tone of the scheme. 

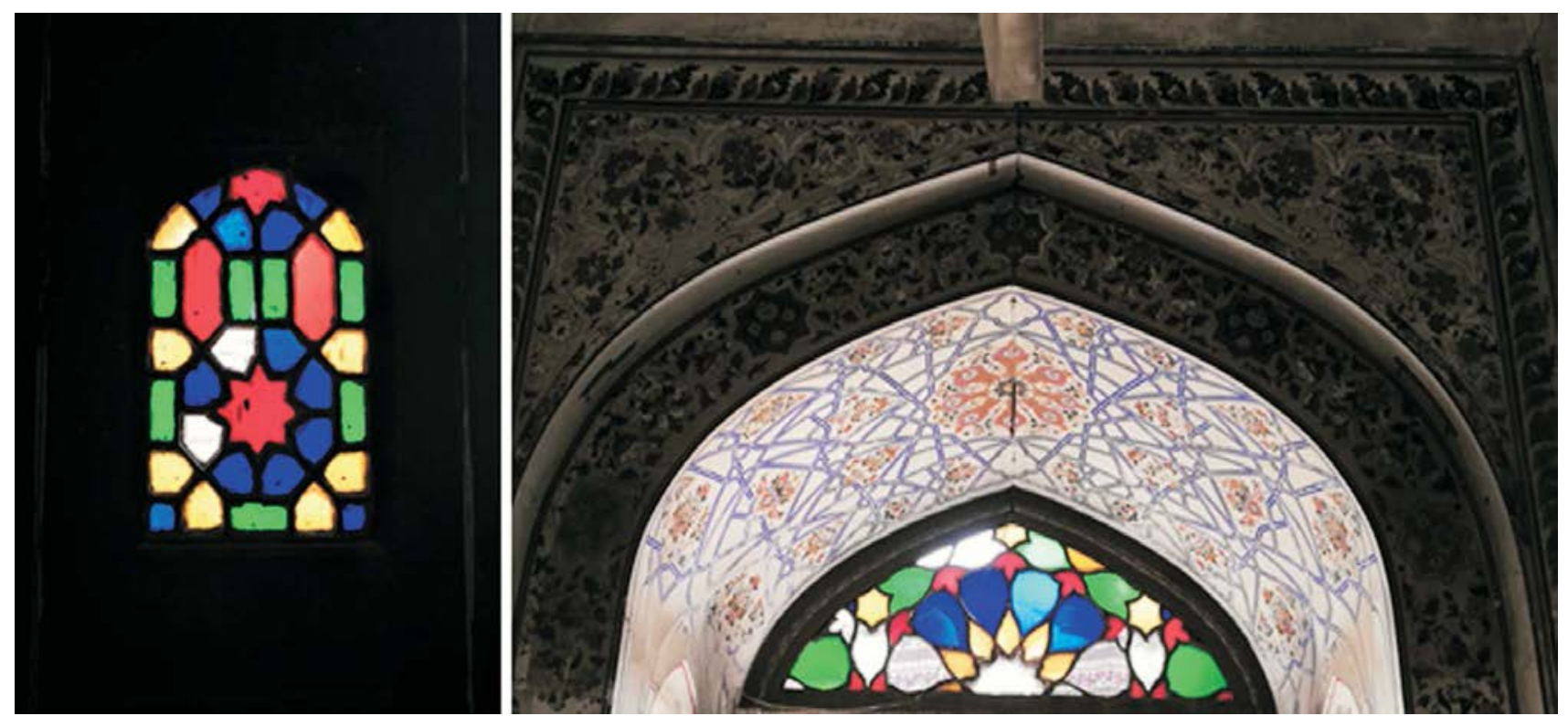

Figure-16: Close-up view of windows in the main hall.

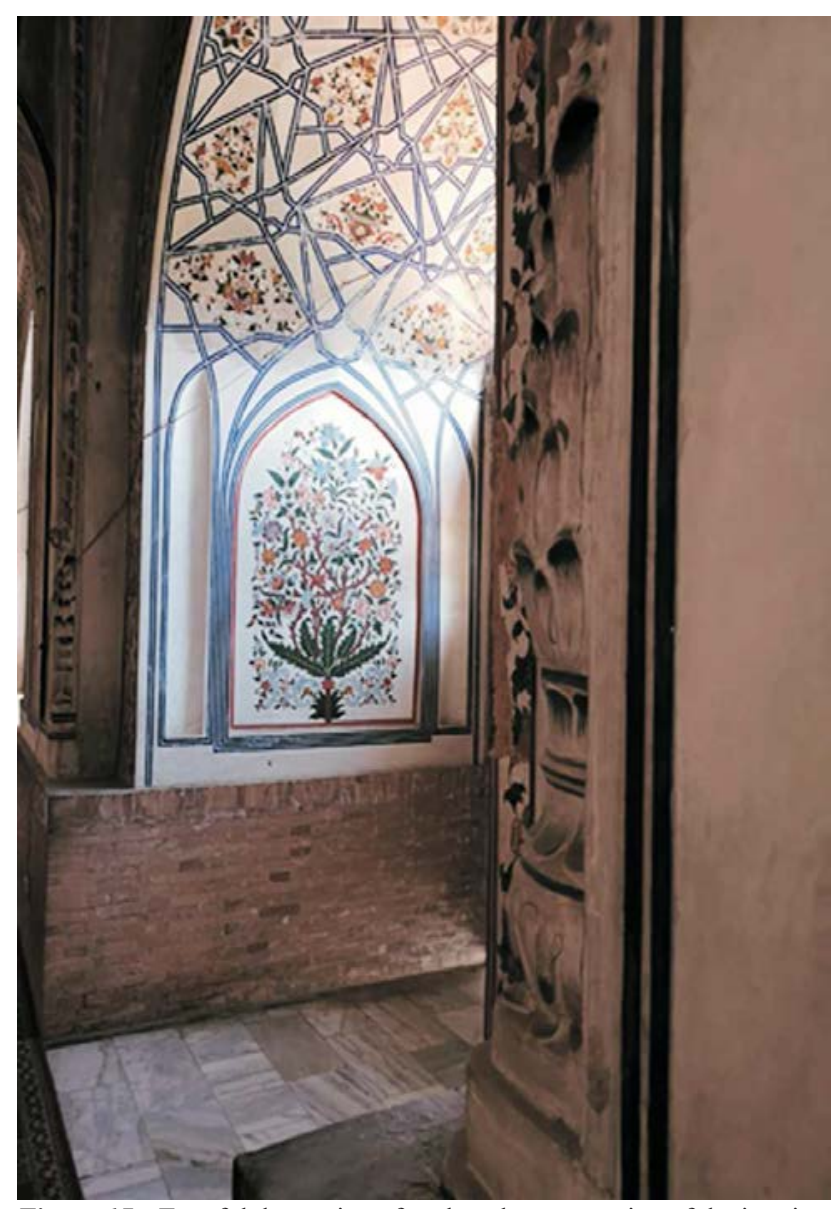

Figure-17: Tasteful decoration of each and every portion of the interior.

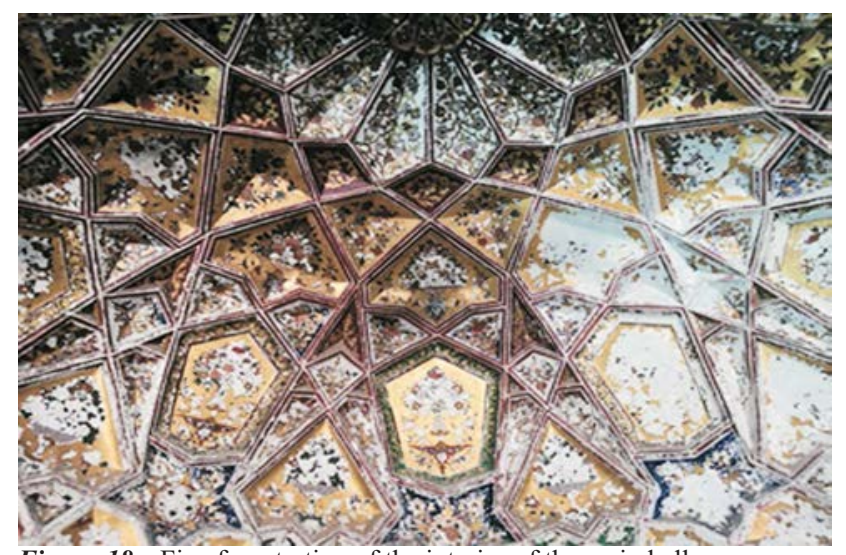

Figure-18: Fine fenestration of the interior of the main hall.

it has been recorded as having been originally built in 1756 (Raverty, 1852). According to Hunter though, Mahabat Khan was a General in the army of Emperor Jehangir and the construction of the Mosque is attributed to him, and therefore estimated to have taken place in the latter half of the 17th century (Hunter, 1887). This Mosque has been referred to as 'the finest public building in the city' in the Gazetteer of the Peshawar District, 1897-98 (Punjab Gazetter, 1989).

This building is recorded to have suffered governanceordered destruction or rather desecration, under the rule of Hari Singh Nalwa in 1834-38 (Caroe, 1958). It is reported by Caroe to have been repaired in the late nineteenth century by the British rulers at that time (Caroe, 1958). After independence of Pakistan in 1947 it was handed over to the 
Auqaf Department, and a number of maintenance works have been conducted since 1949 .

\section{An Inventory of Urgently Required Repairs}

At present the Mosque is in need of urgent repairs due to a long delay in work that was approved in 2016 but has not been carried out to date (Hidayat, 2017). This delay has been due to a dispute between two government departments on the decision to relocate the shops surrounding the Mosque (Akbar, 2019). Meanwhile the condition of the Mosque is worsening, and requires immediate work, as identified through an inventory survey of the main hall carried out by students of the Architecture Department of City University, Peshawar (Figure 19). Three groups were formed to note down observations in the south, centre and north portions of the hall. Symbols of different colours and shapes were used to note the number of locations of four types of needed repairs, namely, plasterwork, paintwork (ornamental), glasswork and woodwork, as listed in Table 1.

\section{RECOMMENDATIONS FOR A PARTICIPATORY APPROACH}

Survey results listed here denote the magnitude of degradation that has already occurred and is progressing due to delay in attention. Any damage in plaster weakens the bonding of all plasterwork at the edges and therefore the damage spreads at an increasing rate if not repaired immediately. This situation in turn underscores the importance of resolving the dispute over relocation of surrounding shops that is causing the delay in repairs (Akbar, 2019). It is imperative for architectural conservation projects to adopt a participatory approach to avoid disputes of interest, as is the standard practice internationally (Ashley, et.al, 2015; Heras, et.al., 2019; Stubbs and Thomson, 2016; Van der Hoeven, 2018; Zang and Van Gorp, 2018). On the basis of the participatory approach practiced globally for architectural conservation projects, the following recommendations can be made for expediting the execution of repair work at Mahabat Khan Mosque:

- An internationally recognised expert on the implementation of participatory methods in architectural conservation work should be engaged.

- All stakeholders should be invited for a public event, such as a seminar, for voicing their viewpoints and then the expert facilitator, as recommended above, can assist in developing a consensus.

- If there is a need to financially support the relocation of the surrounding shops then that support should be arranged by the government.
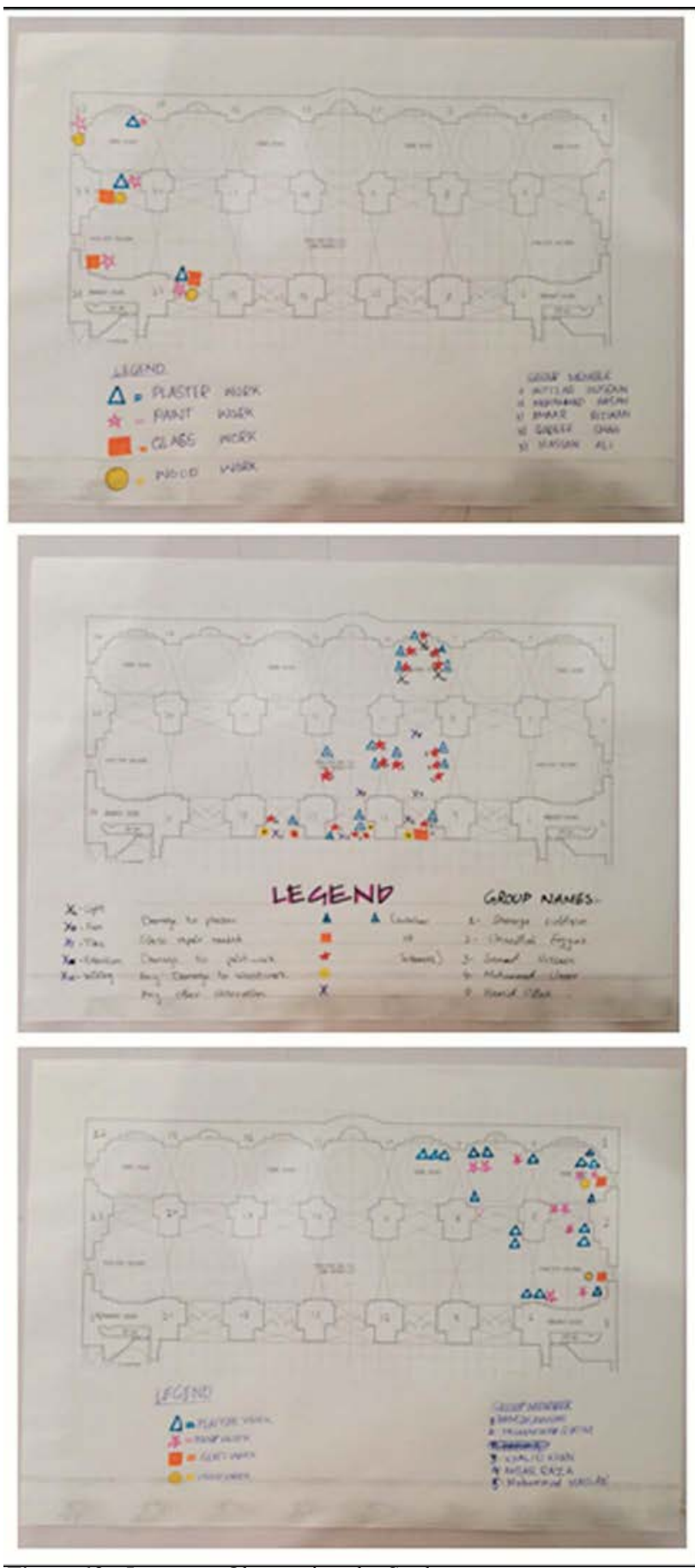

Figure-19: Inventory Observations by Students.

- If one of the concerned government departments has a regular income generation attached with the shops, as indicated in the public statement made via news coverage on this subject, than the same amount of regular income should be arranged from an alternative source for that department (Akbar, 2019). 
Table-1: Cagtegories of Accessibility Zones.

\begin{tabular}{|l|c|l|}
\hline Types of Work & No. of Locations & \multicolumn{1}{c|}{ Notes / Observations } \\
\hline Plasterwork & 60 & $\begin{array}{l}\text { Most of these locations are actively deteriorating, and further delay may } \\
\text { escalate the scope and cast of work. }\end{array}$ \\
\hline Paintwork & 58 & $\begin{array}{l}\text { Any further deterioration may lead to large patches of missing paint and } \\
\text { colour matching will be difficult. }\end{array}$ \\
\hline Glasswork & 11 & $\begin{array}{l}\text { This may require replacement of all panes of the same stain shade, because } \\
\text { any slight difference in shade will damage the whole effect of the stained } \\
\text { glass decor. }\end{array}$ \\
\hline Woodwork & 11 & $\begin{array}{l}\text { Whole panels may require replacement to avoid any aesthetically } \\
\text { unacceptable joints in the carving. }\end{array}$ \\
\hline Total & 140 & $\begin{array}{l}\text { This is modest observation for the purpose of highlighting the extensive } \\
\text { scope and urgency of the required work, and actuall number of } \\
\text { locations may be higher. }\end{array}$ \\
\hline
\end{tabular}

Above recommendations should be implemented immediately to prevent further escalation of repair cost, because the delay is worsening the condition of the building.

\section{CONCLUSION}

Mughal architectural heritage is unique to the subcontinent. It has a distinct quality of inspiring an overpowering awe in a viewer. This feeling is deeply visceral and transcends any conscious ideas or thoughts. It is a heritage to be cherished and passed on to future generations. Its strength makes attempts to divide this region's people on the basis of political or ideological rationalisations appear superficial and fleeting in comparison. This paper has presented the Mahabat Khan Mosque as the western most demarcation of Mughal architectural heritage. Photographs from special angles have been shared to highlight the potential of this magnificent heritage to serve as a narrative that unifies the people of the region. This narrative can serve to counter the separatist narratives being propagated by various politicians to divide the people and promote violence. Mughal architecture can unite the people by its sheer beauty and grandeur. This paper has attempted to forestage this potential as a case for a fresh investment into the preservation and restoration of the Mahabat Khan Mosque. Results from a fresh survey of the state of disrepair have been shared to demonstrate the urgency of the situation. In the backdrop of this whole discussion the recommendations for a participatory approach to resolve delays acquires an undeniable significance.

\section{REFERENCES}

Akbar, S., 16th May 2019, "Peshawar's Majestic Mahabat Khan Mosque In Dilapidated Condition Due To Negligence Of Authorities", Naya Daur, viewed 29-09-2019, from https:/nayadaur.tv/2019/05/peshawars-majestic-mahabat-khanmosque-in-dilapidated-condition-due-to-negligence-of-authorities/

Alfieri, B. M. and Borromeo, F., 2000, Islamic Architecture of the Indian Subcontinent, London, Lawrence Prince Publication.

Ardalan, N. and Bakhtiar, L., 1999, The Sense of Unity: The Sufi Tradition in Persian Architecture, Amsterdom ABC International Group INC

Ashley, K. S., Osmani, M., Emmitt, S., Mallinson, M., and Mallinson, H., 2015, "Assessing stakeholders' perspectives towards the conservation of the built heritage of Suakin, Sudan", International Journal of Heritage Studies, 21(7): 674697.

Brown, P., 2013, Indian Architecture (The Islamic Period), Redditch, Read Books Limited.

Buttimer, A., and Seamon, D., 2015, The Human Experience of Space and Place, New York, Routledge Caroe, O. K., 1958, The Pathans, 550 B.C.-A.D. 1957, New York, MacMillan. 
Dani, A. H.,1995, Peshawar: Historic City of the Frontier, Lahore, Sang-e-Meel Publications. Day, C., 2007, Places of the Soul, USA, Architectural Press.

Foster, S., 2004, Islam + Architecture: The Use of Geometry in Islamic Lands (Vol. 74), Chichester, UK. Frishman, M., Khan, H. U. and Al-Asad, M., 2002, The Mosque: History, Architectural Development and Regional Diversity, London, Thames and Hudson.

Gray, M., and Hancock, G., 2007, Sacred Earth: Places of Peace and Power, UK, Sterling Publishing Company.

Heras, V. C., Moscoso Cordero, M. S., Wijffels, A., Tenze, A. and Jaramillo Paredes, D. E., 2019, "Heritage Values: Towards a Holistic and Participatory Management Approach", Journal of Cultural Heritage Management and Sustainable Development, 9(2): 199-211.

Hidayat, 10th May 2017, "K-P Govt. to Spend Rs88m on Mahabat Khan Mosque uplift", Express Tribune. viewed 12-122019, from https://tribune.com.pk/story/1405741/k-p-govt-spend-rs88m-mahabat-khan-mosque-uplift/

Hunter, W. W., 1887, The Imperial Gazetteer of India, London, Trübner \& Company.

Hussain, A., 1998, The Frontier Town of Peshawar: A Brief History, Maumee, Literary Circle of Toledo.

Jaffar, S. M., 1940, "A Monument of the Mughal Period: Mosque of Mahabat Khan in Peshawar", Islamic Culture, 14: 30-33.

Lewcock, R., 1995, "Architects, Craftsmen and Builders: Materials land Techniques", In E. J. Grube and G. Michell (Eds.), Architecture of the Islamic World: Its History and Social Meaning, London, Thames \& Hudson, p. 112.

Punjab Gazetter, 1989, Gazetteer of the Peshawar District, 1897-98, Lahore, Government of Pubjab.

Raverty, H. G., 1852, "Account of the City and Province of Peshawar, The Transactions of the Bombal" Gographical Society, Vol X: 327-346.

Shah, I., 1996, "Calligraphic Specimens in the Mahabat Khan Mosque, Peshawar", Journal of the Pakistan Historical Society, 44(4): 389-410.

Shah, I., 1997, "The Mahabat Khan Mosque: Historical Perspective", Journal of the Pakistan Historical Society, 45(3): 315-324.

Shah, I., 1999, "The Mahabat Khan Mosque: A Comparative Study", Journal of the Pakistan Historical Society, 47(4): 97.

Shah, I., 2016, "Hindu Iconography in the Gor Khatri Temple (Peshawar): Sacred Imagery Painted in the Eaiva Shrine", South Asian Studies, 32(2): 185-198.

Sternberg, E. M., 2009, "Healing Gardens and my Place of Peace", Healing Spaces, Boston, Harvard University Press.

Stubbs, J. H., and Thomson, R. G., 2016, Architectural Conservation in Asia: National Experiences and Practice, London and New York, Routledge.

TKCP, 2018, "Peshawar", viewed 05-06-2019 from http://tourism.kp.gov.pk/page/peshawar

Van der Hoeven, A., 2018, "Valuing Urban Heritage Through Participatory Heritage Websites: Citizen Perceptions of Historic Urban Landscapes", Space and Culture, London, Sage Publishers, p. 1-20.

Zang, X., and Van Gorp, B., 2018, "Assessing the Potential of Resident Participation in Local Heritage Conservation, the Case of Qingdao, China", Urban Renewal, Community and Participation, New York, Springer, p. 141-159. 